\title{
DEVELOPING BEST PRACTICES OF TEACHER INDUCTION
}

\author{
Lori L. Moore, Assistant Professor \\ Texas A\&M University \\ Benjamin G. Swan, Assistant Professor \\ University of Idaho
}

\begin{abstract}
Problems and challenges faced by beginning teachers have been well documented in the literature and have created the need for teacher induction programs in all disciplines, including agricultural education. This paper used literature from inside and outside the agricultural education discipline to identify and describe best practices in teacher induction yielding a framework called the Best Practices of Teacher Induction for Agricultural Education. This framework is based on the work of Camp and Heath (1988), who identified four contributor groups responsible for teacher induction, and the work of Stansbury and Zimmerman (2000), who identified high and low intensity teacher induction activities. Within the framework, the roles and responsibilities of four contributor groups (local school districts, professional associations, state department of education, and teacher educators) have been described within the context of both high and low intensity activities.
\end{abstract}

\section{Introduction and the Problem}

In 1987, Schuman (as cited in Nesbitt \& Mundt, 1993) went so far as to say that teaching is perhaps the most difficult of all professions to master. Given the fact that beginning teachers are expected to perform the same jobs at the same level as veteran teachers, it is no surprise that the first years of teaching are quite challenging. As early as the 1980s, Scott (1988) saw the issue of how to provide an induction program that will reduce the problems and challenges faced by beginning vocational teachers as a critical issue facing the profession. It is still a problem facing the agricultural education profession. In fact, one of the priority initiatives included in the National Research Agenda: Agricultural Education and Communication 2007-2010 was to "develop and assess effective induction models of early career teachers" (Osborne, 2007).

The concept of teacher induction is well accepted (Camp \& Heath, 1988; Fessler \& Christensen, 1992; Houle, 1980). According to Blair-Larsen and Bercik (1992), "Teacher induction is defined as the period of transition from student to professional when beginning teachers are offered supervision and support as they adjust to their new roles" (p. 25). Sprinthall, Reiman, and Thies-Sprinthall (1996) identified four goals of teacher induction programs: (1) to improve learning and teaching for students, (2) to retain and induct novice teachers, (3) to reward and revitalize experienced teachers in mentor roles, and (4) to increase professional efficacy.

Problems and challenges faced by first year teachers have been well documented in agricultural education (Joerger, 2002; Joerger \& Boettcher, 2000; Mundt, 1991; Mundt \& Connors, 1999; Myers, Dyer, \& Washburn, 2005; Talbert, Camp, \& HeathCamp, 1994) and other teaching disciplines (Brock \& Grady, 1998; Veenman, 1984). Brock and Grady reported the following rank-ordered list of problems faced by beginning teachers: (1) classroom management and discipline, (2) working with mainstreamed students, (3) determining appropriate expectations for students, (4) dealing with stress, (5) handling angry parents, (6) keeping up with paperwork, (7) grading/evaluating student work, 
handling student conflicts, (9) pacing lessons, (10) varying teaching methods, (11) dealing with students of varying abilities, and (12) feeling inadequate as a teacher. Within agricultural education, Mundt and Connors (1997) identified categories of problems and challenges faced by beginning agriculture teachers. In their study, the top five ranked categories were: (1) managing the overall activities of the local FFA chapter, (2) balancing professional and personal responsibilities and maintaining personal motivation and a positive outlook, (3) properly managing your time, completing paperwork and meeting required deadlines, (4) building the support of faculty, counselors and administrators within the school system, and (5) using proper classroom management strategies and dealing with student discipline problems. More recently, Myers et al. (2005) conducted a Delphi study to identify major issues faced by beginning agriculture teachers. The top five ranked categories in their study were: (1) organizing an effective alumni chapter, (2) organizing and effective advisory committee, (3) organizing and planning FFA chapter events and activities, (4) management of student discipline in the classroom, and (5) recruiting and retaining alumni members. The differences between rank-orders of problems faced by teachers in the Brock and Grady (1998) study and the studies in agricultural education are no doubt due to the additional responsibilities agriculture teachers face with respect to $\mathrm{SAE}$ and FFA program supervision. It is the common problems faced by all teachers coupled with the additional responsibilities of agriculture teachers that justify the need for teacher induction programs in agricultural education.

Although numerous studies in agricultural education have examined various components of the induction process, such as needs of first-year teachers and the role of mentors, few have focused on the program as a whole. There are various types of teacher induction programs ranging from those that are state mandated and state funded to those that are completely voluntary and not state funded (Gold, 1996). However, the quality and substance of these existing programs for teacher induction varies (Kelley, 2004). Sprinthall et al. (1996) noted that, "Decisions about the content and character of teacher induction programs are most often based on political and legislative mandate rather than sound educational planning" (p. 691). Brock and Grady (1998) noted that "although most of the literature on teacher induction has focused on the importance of mentors, principals are clearly key figures in the induction process" (p. 180). Brock and Grady's comment rings true in agricultural education. Mentoring has been well documented in the literature (Greiman, Walker, \& Birkenholz, 2002; Peiter, Terry, \& Cartmell, 2003a, 2003b, 2005). However, despite being identified as key figures in the process, studies in agricultural education have provided rather negative findings with respect to the level of assistance provided by principals during the induction process. Mundt (1991) concluded that principals were providing little additional help or supervisory assistance to beginning agriculture teachers. Similarly, Greiman et al. (2002) found that beginning teachers were receiving very little program management assistance from administrators, especially related to some of the major categories of need identified by first-year teachers such as time management, balancing personal and professional responsibilities, and in areas unique to agricultural education.

A United States Department of Education report titled, From Students of Teaching to Teachers of Students: Teacher Induction Around the Pacific Rim (Moskowitz \& Stephens, 1996), noted that successful teacher induction programs, no matter the country or discipline, have six characteristics in common: (1) new teachers are viewed as professionals on a continuum, with increasing levels of experience and responsibility and that novice teachers are not expected to perform the same job as veteran teachers without significant support, (2) new teachers are nurtured, including maximum interaction with other teachers, (3) teacher induction is a purposive and valued activity, (4) schools possess a culture of shared responsibility and support such that most staff members contribute to the development of the new teacher, (5) 
assessment is downplayed, and (6) political, financial, and time commitments are sought from relevant authorities. The report went on to describe how the United States differs, and in many cases is lacking, in each of these areas from the teacher induction programs studied, including programs in Japan, New Zealand, and the Northern Territory of Australia.

The major criticism faced by teacher induction programs is the lack of a comprehensive theoretical or conceptual framework for teacher induction (Gold, 1996; Little, 1990; Sprinthall et al., 1996). This is especially evident when synthesizing the literature related to various contributors and activities that have been, or should be, included in teacher induction programs. Stansbury and Zimmerman (2000) did describe specific support strategies that should be included in new teacher programs. They classified the strategies as either low intensity, those that make minimal demands on district and school resources, or high intensity, those that are more taxing but at the same time more effective (Stansbury \& Zimmerman). Although the authors did describe specific support strategies, they focused solely on those offered by the school district without mention of other contributor groups and the activities that they should offer within the program. Within agricultural education, Nesbitt and Mundt (1993) described the three components of a program housed within the Agricultural and Extension Education Department at the University of Idaho. In their programs, beginning teachers received support by way of individual on-site consultations, seminars, and assignments that could be completed for university credit. The majority of the other studies found within agricultural education focused on a particular aspect of the program, rather than the overall program itself.

\section{Theoretical/Conceptual Framework}

Camp and Heath (1988) identified four contributor groups that should be involved in teacher induction programs for vocational teachers. According to Camp and Heath,

Officials of the state department of education should provide direction, teacher education faculty members should provide a theoretical and research base, the local school administrators should provide support and direct assistance on a day-to-day basis, and members of the profession through professional organizations should provide subject-specific assistance. ( $\mathrm{p}$. 109-110)

The Camp and Heath collaborative approach to teacher induction was the first approach to identify the various contributor groups that should be involved in teacher induction programs specifically designed for vocational teachers. However, within the description of their approach, the authors mentioned only broad roles and responsibilities of each group, not the specific activities each group should be responsible for.

In reference to beginning teachers and induction program activities, Stansbury and Zimmerman (2000) posit, "What lifelines can we offer so they will remain in the profession and develop into highly effective classroom educators?" (p. 2). According to Stansbury and Zimmerman, these lifelines come as either high intensity or low intensity teacher induction activities. They identified specific activities, both high and low intensity, that should be implemented in beginning teacher induction programs (Figure 1). High intensity activities are those that require substantial funding and effort to develop and support beginning teachers including selecting and training effective mentors, providing release time, roving substitute(s) releasing beginning and mentor teachers, mini-courses addressing common challenges, examining evidence and developing reflective practice, and networking new teachers into reflective practice groups (Stansbury \& Zimmerman). Although they require more money and effort, higher intensity activities have shown improved teacher effectiveness (Stansbury \& Zimmerman). Low intensity activities are those that require little funding and less effort by all involved compared with high intensity activities, including orienting new teachers, matching beginning and veteran teachers, adjusting working conditions, and 
promoting collegial collaboration (Stansbury \& Zimmerman). Such low intensity efforts suggest that participating beginning teachers have higher retention rates and job satisfaction (Stansbury \& Zimmerman). Low intensity efforts do not appear to develop teacher effectiveness, but address retention issues

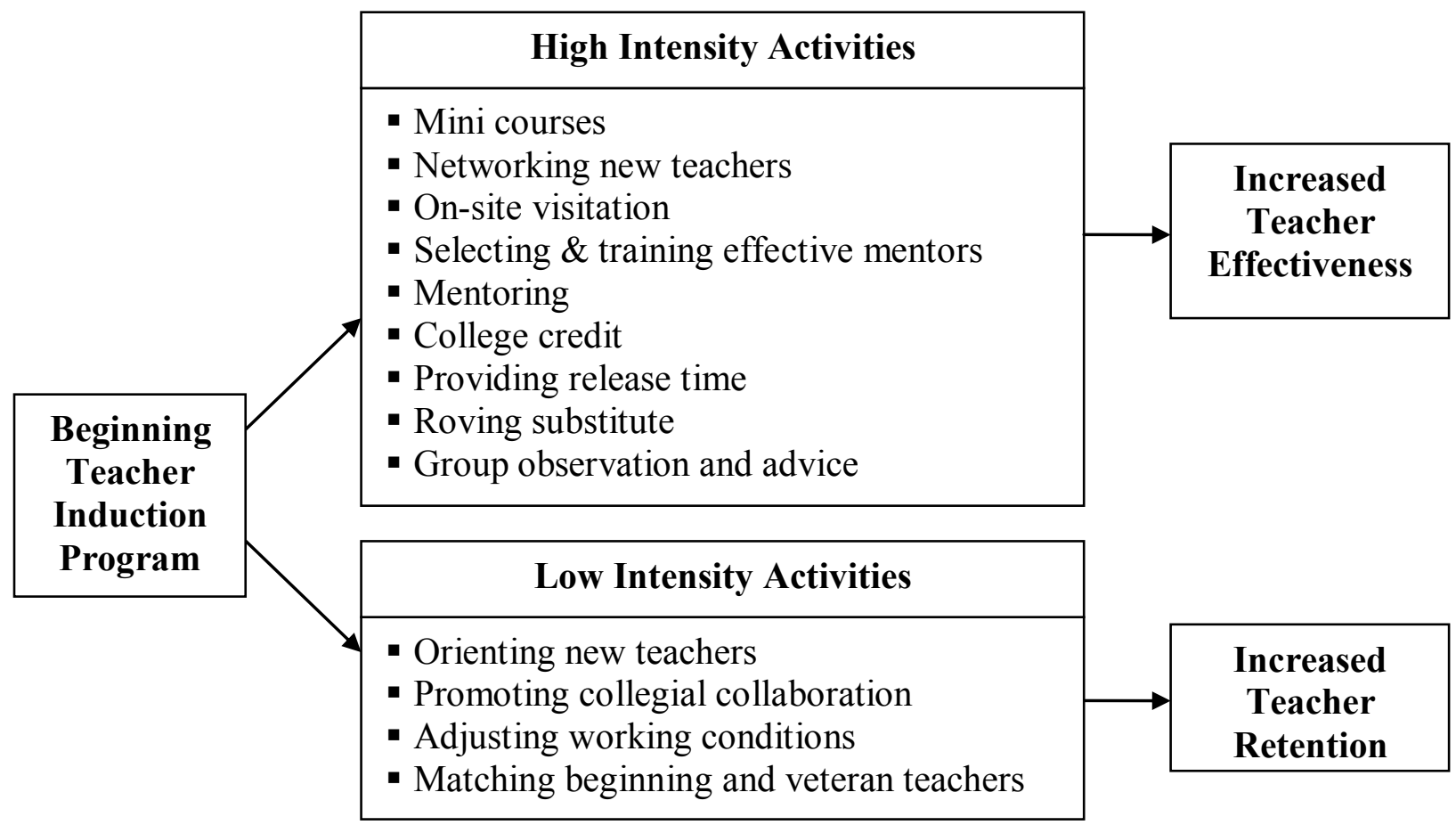

Figure 1. High and low intensity activities in beginning teacher induction.

Purpose

Combining the work of Camp and Heath (1988) with the work of Stansbury and Zimmerman (2000) provided the basis for the creation of the Best Practices of Teacher Induction for Agricultural Education framework, referred to as Best Practices (Figure 2). The contributors' involvements with specific activities are described. 


\begin{tabular}{|c|c|c|c|c|}
\hline \multicolumn{5}{|c|}{ BEST PRACTICES OF TEACHER INDUCTION FOR AGRICULTURAL EDUCATION } \\
\hline \multirow[b]{2}{*}{ ACTIVITY } & \multicolumn{4}{|c|}{ CONTRIBUTORS } \\
\hline & $\begin{array}{c}\text { Local } \\
\text { District }\end{array}$ & $\begin{array}{l}\text { Professional } \\
\text { Association }\end{array}$ & $\begin{array}{l}\text { State Dept. of } \\
\text { Education }\end{array}$ & $\begin{array}{c}\text { Teacher } \\
\text { Education }\end{array}$ \\
\hline $\begin{array}{l}\text { High Intensity } \\
\text { - Selecting \& training effective } \\
\text { mentors }\end{array}$ & $\checkmark$ & $\checkmark$ & & $\checkmark$ \\
\hline - Mentoring & $\checkmark$ & $\checkmark$ & & \\
\hline - College credit & & & & $\checkmark$ \\
\hline - Providing release time & $\checkmark$ & & & \\
\hline - Roving substitute & $\checkmark$ & & & \\
\hline $\begin{array}{l}\text { - Mini-Courses addressing } \\
\text { common challenges }\end{array}$ & $\checkmark$ & $\checkmark$ & $\checkmark$ & $\checkmark$ \\
\hline - Networking new teachers & $\checkmark$ & $\checkmark$ & $\checkmark$ & $\checkmark$ \\
\hline - Group observation \& advice & $\checkmark$ & & & \\
\hline - On-site visitation & $\checkmark$ & $\checkmark$ & $\checkmark$ & $\checkmark$ \\
\hline $\begin{array}{l}\text { Low Intensity } \\
\text { - Orienting new teachers }\end{array}$ & $\checkmark$ & $\checkmark$ & $\checkmark$ & \\
\hline $\begin{array}{l}\text { - Matching beginning \& } \\
\text { veteran teachers }\end{array}$ & $\checkmark$ & $\checkmark$ & & \\
\hline - Adjusting working conditions & $\checkmark$ & & & \\
\hline $\begin{array}{l}\text { - Promoting collegial } \\
\text { collaboration }\end{array}$ & $\checkmark$ & $\checkmark$ & & \\
\hline
\end{tabular}

Figure 2. Best practices of teacher induction for agricultural education.

\section{Description of Best Practices for Teacher Induction Using Supporting Research}

The Best Practices framework includes engaged contributors that organize and provide teacher induction activities. The four engaged contributors are the local district, professional association, state department of education, and teacher education (Camp \& Heath, 1988). Each contributor plays a significant role in preparing, supporting, and developing beginning teachers. The Best Practices identifies which contributor is involved with which activity. Perhaps Talbert et al. (1994) stated it best when they said, "Teacher educators, local educational leaders, state department of education leaders, and leaders of the professional organizations must all accept some responsibility for guiding and nurturing novices" (p. 35). The Best
Practices framework provides a structure for induction activities, provided there is support from various contributors.

\section{High Intensity Activities}

In looking at the Best Practices framework, it is evident that the local district should bear primary responsibility in conducting high intensity activities. However, all four contributor groups should share responsibility for conducting many of the high intensity activities.

Selecting \& Training Effective Mentors. Stansbury and Zimmerman (2000) shared that the minimum criteria for selecting a mentor are that the mentor is a successful classroom teacher, can articulate their practice, and has a level of understanding of how long it takes to get to the teaching level that they themselves are at. Veteran teachers 
identified as potential mentors need to meet the criteria set forth by Stansbury and Zimmerman. In essence, two mentor pools should be identified: one established by the local district consisting of on-site teachers and the other by the professional association consisting of agriculture teachers within the school, local FFA district, or nearby schools who can serve as subject matter mentors. Simon (1989) recommended that "beginning teachers should be allowed to select their own mentor(s)" (p. 223).

It is not enough to simply identify potential mentors who meet the set criteria. Once the potential mentors have been identified, they must then be trained to serve as effective mentors. This training must consist of several elements such as observation skills, strategies for working with adults, cognitive coaching, how to collect evidence of teaching to improve effective teaching, how to identify and communicate beginning teacher strengths, and how to build on those strengths (Stansbury \& Zimmerman, 2000). Furthermore, mentors should not be supervisors and/or in an evaluation role. Peiter et al. (2003a) found that mentoring was viewed by some beginning agriculture teachers as an evaluation program, rather than mentoring. The local district, professional association, and teacher education should prepare mentors.

Mentoring. Careful mentor selection as outlined above combined with mentor training that stresses assessment, as opposed to evaluation, would help ensure that mentoring is helpful to beginning teachers. Beginning agriculture teachers "valued the experiences of current teachers and wished to learn from them"... and sought ..."more advice and ideas on how to engage students in learning, and how to create more experiential activities" (Greiman, Walker, \& Birkenholz, 2005, p. 99). Beginning teachers ranked an informal mentor from the local school as being most helpful, but only $67 \%$ of respondents received this assistance (Greiman et al., 2002). Mentors from within the school district are the responsibility of the local district.

In their study, Greiman et al. (2002) reported that $87 \%$ of beginning teachers received assistance from another agricultural teacher from another school and found the support rather helpful. These subject matter mentors are the responsibility of the professional association. In single teacher departments and some multiple teacher departments, beginning agriculture teachers might need to locate subject matter mentors outside the school as well as an in-school mentor. However, in multiple teacher departments, a fellow agriculture teacher might fulfill both roles. Darling-Hammond (2006) found that expert mentors within the same field as the beginning teacher had the greatest effect on retention and student learning.

College Credit. Mundt and Connors (1997) recommended that beginning teacher assignments be aligned with state mandated reports and embedded within graduate courses for credit to provide recent bachelor degree awardees an opportunity to jumpstart their graduate degree while participating in an induction program. Kelley (2004) found that beginning teachers from six school districts "expressed appreciation for the graduate activities embedded in the induction experience" (p. 445). Beginning teachers agreed $(92 \%)$ that the assignments given within their graduate courses were relevant (Nesbitt \& Mundt, 1993). Franklin and Haverland (2007) reported that 42.8\% of agricultural teacher preparation programs in the Western Region offer college courses primarily designed for beginning teachers. Teacher education is responsible for providing opportunities for beginning teachers to enroll for graduate credit.

Providing Release Time. Simon (1989) found that "subject matter mentors were frustrated with the lack of time they had for communication, observation, and for sharing teaching materials with beginning teachers" (p. 223) and proposed that one period per day be reserved for the mentor and beginning teacher to accomplish such tasks. Though recommended, there is a lack of literature in agricultural education describing the incorporation of such activities in an induction program. Release time should be provided by local school districts and/or administrators.

Roving Substitute. A roving substitute teacher can provide release time for a 
beginning teacher and on-site mentor to meet by the substitute teaching the beginning teacher's class during the mentor's preparation period. The frequency of this occurrence needs to be determined and provided by the local district if normally scheduled release time does not occur.

Mini-Courses Addressing Common Challenges. Mini-courses need to be incorporated into the beginning teacher induction program to meet specific challenges within the topics of FFA, SAE, varying agriculture content, and emerging technologies. Mundt (1991) found it "imperative that the teacher possess management and organizational skills" ( $p$. 23). Mundt and Connors (1999) recommended that "time and organizational strategies be incorporated as components of courses and workshops for" ... "beginning teachers" and that "ideas for building community, parental, faculty, counselor, and administrator support for the program continue to be important components of courses and inservice workshops for"... "beginning teachers" (p.75). Greiman et al. (2002) found that first-year teachers received very little district assistance regarding managing time, balancing responsibilities, and in areas unique to agricultural education. Franklin and Haverland (2007) reported that $66.6 \%$ of teacher preparation programs in the Western Region conduct workshops targeted for beginning teachers. Franklin and Molina (2006) found that nearly $73 \%$ of agricultural teacher education programs across the country conduct workshops targeted for beginning teachers, yet these mini-courses need to be supported and conducted by the local district and between the state department of education, teacher education, and the professional association (Greiman et al., 2005). Furthermore, Mundt and Connors (1997) recommended that "those involved in providing the leadership for the State and National FFA organizations provide guidelines to new teachers for effectively managing the local FFA chapter during the first years of teaching" (p. 75).

Networking New Teachers. Some schools in Switzerland have partnered with neighboring schools to create a network of beginning teachers able to freely discuss and work out issues with a highly trained educator with no report back to the home district (Stansbury \& Zimmerman, 2000). Such networking between teachers addressed some of the challenges of isolation and socialization issues experienced by beginning agriculture teachers (Greiman et al, 2005). The four contributors should coordinate opportunities for beginning agriculture teachers to meet within districts at least once a month with two mentors, one provided by the professional association for program issues, and one from teacher education to address pedagogical issues.

Group Observation \& Advice. Some schools in Japan have all beginning teachers present their "best possible lesson" in a real class observed by their colleagues (Stansbury \& Zimmerman, 2000). Most beginning teachers found the critique and advice quite helpful for their development as a teacher (Stansbury \& Zimmerman). There is a void in the literature related to this activity in the majority of induction programs including those in agricultural education. This form of high intensity activity should be explored and coordinated by the local school district.

On-Site Visitation. All four contributors should make efforts to visit beginning teachers. Anderson, Barrick, and Hughes (1992) found that teacher educators were primarily responsible for coordinating and delivering supervision of first year teachers. Nearly $60 \%$ of the teacher education programs in the Franklin and Molina (2006) study reported supervising beginning teachers in the field. However, only $42.8 \%$ of agriculture teacher programs in the Western Region reported providing on-site supervision of beginning teachers (Franklin \& Haverland, 2007). Following their on-site visits, Nesbitt and Mundt (1993) reported they provided beginning teachers with a written narrative of their visit. The authors went on to report that $84 \%$ of the beginning agriculture teachers in their study found these narratives to be of benefit.

Mundt (1991) found that "beginning teachers would have preferred more inclassroom supervision from the principal" (p. 22). Joerger and Boettscher (2000) 
found that those beginning teachers who received feedback from their principal made a high impact on the beginning teachers. This provides more evidence that principals are key players in teacher induction and that they should increase their efforts to visit beginning teachers.

There is a lack of literature related to the on-site supervision of beginning agriculture teachers from state departments of education and professional organizations. Despite this lack of research, these two groups can, and should, play a significant role in visiting first-year teachers.

\section{Low Intensity Activities}

As with the high intensity activities, the primary responsibility for conducting many of the low intensity activities falls to the local district. However, there are activities in which other contributor groups should be involved.

Orienting New Teachers. Prior to the school year beginning, districts should provide an orientation to new faculty giving an overview of policies, procedures, performance expectations, and site-specific details. This activity is perhaps one of the most popular low intensity activities and is currently included in many teacher induction programs. Of the 56 elementary and high school principals who participated in a study conducted by Brock and Grady (1998), 61\% indicated they offered an orientation for new faculty members before school opened. At first look, the statistics within agricultural education may appear even more impressive. Ninety percent of the first-year teachers included in the Greiman et al. (2002) study reported receiving an orientation to the school before school opened. However, despite such a high percentage of respondents who received orientation to the school, only $60 \%$ felt the local administrator clearly communicated their expectations for the desired performance of the beginning teacher (Greiman et al., 2002). The study also showed that the beginning teachers wanted more assistance with required paperwork such as forms, reports, applications, grants, etc. Therefore, it is recommended that meetings and instruction during the orientation should cover a wide range of topics, including, but not limited to, classroom management, teacher and student handbooks, paper work required of educators, expectations of teacher performance, and reviewing teacher developed classroom expectations and syllabi.

Although much of what has been reported in the literature related to orientation of new teachers focused on the role of the local school district, this is one low intensity activity in which other contributor groups should also be involved, but in slightly different ways. Professional organizations should ensure that beginning agriculture teachers are aware of the organization and the benefits of membership. Furthermore, they should orient new teachers to relevant policies and procedures within the association. The same is true for state departments of education. Representatives of the state department of education should orient beginning agriculture teachers to the expectations of the state department prior to the start of the school year.

Matching Beginning \& Veteran Teachers. Simply matching beginning and veteran teachers and encouraging a buddy/cheerleader relationship is considered low intensity because of the lack of direction and planned effort. This pairing of teachers should occur before the school year begins. Often, agriculture teachers are paired with nonagriculture teachers on site. In essence, this activity creates an opportunity for a very informal in-school mentor relationship to develop. Despite being low intensity, the value of in-school mentors for beginning agriculture teachers has been noted. As Simon (1989) stated, "In-school mentors helped beginning teachers understand the political aspects of the school, including standard operating procedures, school policies and practices and the importance of the teacher's union" (p. 222).

Adjusting Working Conditions. Although beginning agriculture teachers may teach the same number of periods per day as other teachers on campus, including beginning teachers in other disciplines, they often have a higher number of different classes to prepare for. Couple this with FFA and SAE supervision responsibilities and it is no 
surprise that time management has been cited in the literature as a major problem faced by beginning agriculture teachers (Mundt \& Connors, 1999; Talbert et al., 1994). Reducing the number of classes to prepare for during the first year would be advantageous. An example of this would be having two periods of the Agricultural Science I, thus providing new teachers less required time preparing and more time improving instruction because of teaching the content more than once. Another example of adjusting work conditions would be to provide beginning teachers an additional planning period. Joerger and Boettcher (2000), concluded that "though it seldom occurred, beginning agricultural education teachers believed that having an extra planning period would have had a major impact on their teaching experience" (p. 594). Any additional time would also provide the beginning agriculture teacher additional time to focus on other components of their job such as FFA program responsibilities, another area identified in the literature as a significant problem faced by beginning agriculture teachers (Myers et al., 2005; Mundt \& Connors, 1997).

Promoting Collegial Collaboration. Collegial collaboration is considered a low intensity activity because it generally occurs rarely and has no cost to it. When teachers are grouped across grade level or within departments to address classroom and school challenges, this is considered collegial collaboration. Beginning teachers can be valuable in these situations as they bring a fresh perspective and have completed coursework more recently than veterans. The agriculture teacher is often in a small department and should be grouped with other career and technology teachers, thus common topics can be worked on between the different disciplines.

The need for collegial collaboration is further demonstrated by feelings of isolation often felt by beginning agriculture teachers due to the location of the agricultural education department or a lack of contact with other teachers (Greiman et al., 2005; Talbert et al., 1994). Greiman et al. (2005) noted that "novice teachers experienced feelings of isolation as they began their teaching career, and expressed a need for socialization within the school" (p. 102).

Other contributor groups, especially professional associations, should play a role in promoting collegial collaboration. It is not enough for a new teacher to feel part of the school community; they should also feel as though they are part of the agricultural education community as well. At the very least, association members on the local level should make sure beginning agriculture teachers are introduced to other agriculture teachers in the area.

\section{Conclusions and Recommendations}

Based on a review of literature, within and outside agricultural education, lifelines in the form of low and high intensity activities and which of four contributor groups should be involved in the administration/implementation of each activity has been proposed in the Best Practices of Teacher Induction for Agricultural Education creating a framework for investigation. As a result, there is still much work to do.

If it takes a village to raise a child, then perhaps it takes four contributor groups to "raise" a teacher. Anecdotal evidence suggests that not much has changed since Nichols and Mundt (1993) stated, "It appears that more communication and dialogue must occur between various positions within education. When this occurs, beginning teachers will benefit." (p. 232). Although the proposed Best Practices identified several activities requiring the participation of all four contributor groups, research efforts need to be conducted to determine the willingness and agreement of each to implement the identified activities. It would also be beneficial to involve beginning teachers themselves in this type of research.

The Best Practices described in this paper rely heavily on the participation of local school principals and administrators. However, studies in agricultural education have shown a lack of participation by this important group (Greiman et al., 2002; Mundt, 1991). Future studies should identify barriers preventing principals from being more involved in the induction activities of 
beginning agriculture teachers. Furthermore, the level of training related to teacher induction included in the preparation programs of future principals should be investigated.

The incorporation of some of the activities included in the Best Practices framework have not been well documented in the agricultural education literature. Future studies should be conducted to determine the effects of providing release time for mentor teachers and beginning teachers to meet on a regular basis. Studies should also be conducted to assess the value of on-site supervision by state staff members and representatives of professional organizations as well as peer evaluations by other teachers within a beginning teacher's own school. These studies should describe the perceptions of participants as well as investigate the impact of these activities on both retention of beginning teachers and factors such as job stress and job satisfaction.

"It is essential that the more focused questions regarding in-depth studies on the context, content, process, and consequences of providing support be addressed if the support components of programs are to be effective" (Gold, 1996, p. 587). Gold further noted that "...factors interact in a myriad of ways to create a total experience" and "to focus on one or only a few of these is insufficient" (p. 589). As Joerger \& Boettscher (2000) noted, the agricultural education profession needs to continue to explore the perceptions of beginning agriculture teachers related to the teacher induction activities they experienced.

In terms of funding beginning teacher induction, the state department of education has traditionally had major responsibility (Anderson et al., 1992). This study had proposed the activities and contributor groups responsible for each activity. However, no attempt has been made to mandate the group(s) responsible for funding the entire program. Several funding models may be possible and various states may see funding issues differently. In the end, the manner in which the program is funded is not as important as the fact that the program is funded.
Though it was outside the scope of this study, research in the area of the impact of the teacher induction activities included in the proposed Best Practices on job stress, job satisfaction, and the self-efficacy of beginning agriculture teachers is also warranted.

\section{References}

Anderson, T. J., Barrick, R. K., \& Hughes, M. (1992). Responsibilities of teacher education for vocational teacher professional development programs. Journal of Agricultural Education, 33(2), 43-50.

Blair-Larsen, S. M., \& Bercik, J. T. (1992). A collaborative model for teacher induction. Education, 113(1), 25-31.

Brock, B. L., \& Grady, M. L. (1998). Beginning teacher induction: The role of the principal. The Clearing House, 71(3), 179183.

Camp, W. G., \& Heath, B. (1988). Structuring the induction process for beginning vocational teachers. In W. G. Camp and B. Heath (Eds.), On becoming a teacher: Vocational education and the induction process (pp. 105-119). Berkley, CA: National Center for Research in Vocational Education.

Darling-Hammond, L. (2006). Powerful teacher education. Jossey-Bass: San Francisco, CA.

Fessler, R., \& Christensen, J. C. (1992). The teacher career cycle: Understanding and guiding the professional development of teachers. Needham Heights, MA: Allyn and Bacon.

Franklin, E. A., \& Haverland, E. (2007). Teacher induction programs in agricultural education - Description of the role of Western Region AAAE higher education teacher preparation programs. Proceedings of the 26th Western Region Agricultural Education Research Conference, Cody, WY. 
Franklin, E. A., \& Molina, Q. (2006). Teacher induction program in agricultural education: Description of the role of AAAE higher education teacher preparation programs. Proceedings of the 33rd National Agricultural Education Research Conference, Charlotte, NC.

Gold, Y. (1996). Beginning teacher support: Attrition, mentoring, and induction. In J. Sikula, T. J. Buttery, \& E. Guyton (Eds.), Handbook of research on teacher education (2nd ed.) (pp. 548-594). New York: Simon \& Schuster Macmillan.

Greiman, B. C., Walker, W. D., \& Birkenholz, R. J. (2002). The induction of novice teachers: A study of first-year agriculture teachers in Missouri. Proceedings of the 29th National Agricultural Education Research Conference, Las Vegas, NV.

Greiman, B. C., Walker, W. D., \& Birkenholz, R. J. (2005). Influence of the organizational environment on the induction stage of teaching. Journal of Agricultural Education, 46(3), 95-106.

Houle, C. O. (1980). Continuing learning in the professions. San Francisco: Jossey-Bass.

Joerger, R. M. (2002). A comparison of the inservice education needs of two cohorts of beginning Minnesota agricultural education teachers. Journal of Agricultural Education, 43(3), 11-24.

Joerger, R., \& Boettcher, G. (2000). A description of the nature and impact of teaching events and forms of beginning teacher assistance as experienced by Minnesota agricultural education teachers. Journal of Agricultural Education, 41(4), 104-115.

Kelley, L. M. (2004). Why induction matters. Journal of Teacher Education, 55(5), 438-448.

Little, J. W. (1990). The mentor phenomenon and the social organization of teaching. Review of Research in Education, 16, 297-351.

Moskowitz, J., \& Stephens, M. (Eds.). (1996). From students of teaching to teachers of students: Teacher induction around the Pacific Rim. United States Department of Education.

Mundt, J. (1991). The induction year: A naturalistic study of beginning secondary teachers of agriculture in Idaho. Journal of Agricultural Education, 32(1), 18-23.

Mundt, J. P., \& Connors, J. J. (1997). Problems and challenges associated with the first years of teaching agriculture: A framework for preservice and inservice education. Proceedings of the 24th National Agricultural Education Research Meeting, Las Vegas, NV, (pp. 67-76).

Mundt, J. P., \& Connors, J. J. (1999). Problems and challenges associated with the first years of teaching agriculture: A framework for preservice and inservice education. Journal of Agricultural Education, 40(1), 38-48.

Myers, B. E., Dyer, J. E., \& Washburn, S. G. (2005). Problems facing beginning agriculture teachers. Journal of Agricultural Education, 46(3), 47-55.

Nesbitt, D. L., \& Mundt, J.P. (1993). An evaluation of the university of Idaho beginning teacher induction program. Journal of Agricultural Education, 34(2), 11-17.

Nichols, L. S., \& Mundt, J. P. (1993). Perceptions of critical competencies for the survival of beginning agriculture and home economics teachers from four educational perspectives. Proceedings of the 20th National Agricultural Education Research Meeting, Nashville, TN.

Osborne, E. W. (Ed.). (2007, May). National research agenda for agricultural education and communication 2007-2010. Retrieved October 3, 2008, from http://aaaeonline.org/files/researchagenda_lo nglores.pdf. 
Peiter, R. L., Terry, R., Jr., \& Cartmell, D. D., II. (2003a). A state mandated induction program: Mentorship experiences for first year agricultural education teachers. Proceedings of the 30th National Agricultural Education Research Conference, Orlando, FL.

Peiter, R. L., Terry, R., Jr., \& Cartmell, D. D., II. (2003b). Identification of mentors for first year agricultural education teachers. Proceedings of the 30th National Agricultural Education Research Conference, Orlando, FL.

Peiter, R. L., Terry, R., Jr., \& Cartmell, D. D., II. (2005). Mentoring first year agricultural educators: Examining a statemandated induction program. Journal of Agricultural Education, 46(1), 11-19.

Scott, J. L. (1988). Induction needs of beginning vocational teachers without teacher education degrees. In W. G. Camp and B. Heath (Eds.), On becoming a teacher: Vocational education and the induction process (pp. 69-90). Berkley, CA: National Center for Research in Vocational Education.
Simon, J. (1989). Mentor teachers' perceptions of the mentoring experience. Proceedings of the 16th Annual National Agricultural Education Research Meeting, Orlando, FL, (pp. 217-224).

Sprinthall, N. A., Reiman, A. J., \& Thies-Sprinthall. (1996). Teacher professional development. In J. Sikula, T. J. Buttery, \& E. Guyton (Eds.), Handbook of research on teacher education (2nd ed.) (pp. 666-703). New York: Simon \& Schuster Macmillan.

Stansbury, K., \& Zimmerman, J. (2000). Lifelines to the classroom: Designing support for beginning teachers. (WestEd Knowledge Brief). San Francisco: West Ed.

Talbert, B. A., Camp, W. G., \& HeathCamp, B. (1994). A year in the lives of three beginning agriculture teachers. Journal of Agricultural Education, 35(2), 31-36.

Veenman, S. (1984). Perceived problems of beginning teachers. Review of Educational Research, 54(2), 143-178.

LORI L. MOORE is an Assistant Professor in the Department of Agricultural Leadership, Education, and Communications at Texas A\&M University, 128 Scoates Hall, MS 2116, College Station, TX 77843-2116. E-mail: 1lmoore@tamu.edu.

BENJAMIN G. SWAN is an Assistant Professor in the Department of Agricultural and Extension Education at the University of Idaho,1134 W. Sixth Street, PO Box 442040, Moscow, ID 83844-2040. E-mail: bswan@uidaho.edu. 